\title{
Septal aperture aetiology: still more questions than answers
}

\author{
A. Myszka \\ Department of Human Evolutionary Biology, Institute of Anthropology, Faculty of Biology, Adam Mickiewicz University, \\ Poznan, Poland
}

[Received 28 July 2014; Accepted 17 September 2014]

\begin{abstract}
Many theories have been suggested in order to explain the aetiology of septal aperture. The influence of genes, the size and shape of ulna processes, joint laxity, bone robusticity, osteoarthritis, and osteoporosis has been discussed; however, the problem has not yet been solved. The aim of the study was to examine the correlations between musculoskeletal stress markers, humeral robusticity and septal aperture. Additionally, the frequency of septal aperture according to sex, age, and skeletal side had been analysed. The skeletal material had come from a medieval cemetery in Cedynia, Poland. Skeletons of 201 adults (102 males, 99 females) had been examined and septal aperture had been scored. Six muscle attachment sites of upper limb bones had been analysed. Humeral robusticity had been calculated by use of the humeral robusticity index. The frequency of septal aperture among the population from Cedynia is $7.5 \%$. There are no differences in septal aperture prevalence between males and females, the skeletal sides or age groups. In the analysed material, males with less developed muscle markers of right upper bones proved a higher predictable rate in having septal aperture $(R=-0.34)$. On the left bones and among females, the converse correlation had also been found, but it is not statistically significant. The correlation between septal aperture and humeral robusticity is converse, yet small and insignificant. These results can confirm the theory of joint laxity and suggest that stronger bones (heavier muscles, more robust bones) increase joint tightness, and therefore protect the humeral lamina from septal aperture formation. But this theory needs a further detailed analysis. (Folia Morphol 2015; 74, 2: 219-224)
\end{abstract}

Key words: septal aperture, subtrochlear foramen, musculoskeletal stress markers, humeral robusticity, skeletal material

\section{INTRODUCTION}

The septal aperture of the humerus (also called the subtrochlear foramen, intercondylar foramen) is a perforation in the bony lamina that separates the olecranon and coronoid fossae in the distal part of the bone (Fig. 1) [22]. The lamina is present until 7 years of age, than is occasionally absorbed to a subtrochlear foramen [15]. Individuals with this trait may be able to overextend the elbow joint [8]. The frequency of the foramen among mankind ranges from about $0.3 \%$ to $60 \%$, in different races [for the details see $18,28,34,35,39]$. The cause of septal aperture has been widely discussed; however, the problem has not been solved yet. Some authors have suggested that it is an inherited characteristic [12, 37]. The marked variation in a frequency of septal aperture between different human populations has been given as evidence for genetic aetiology of the trait [22]. A number 


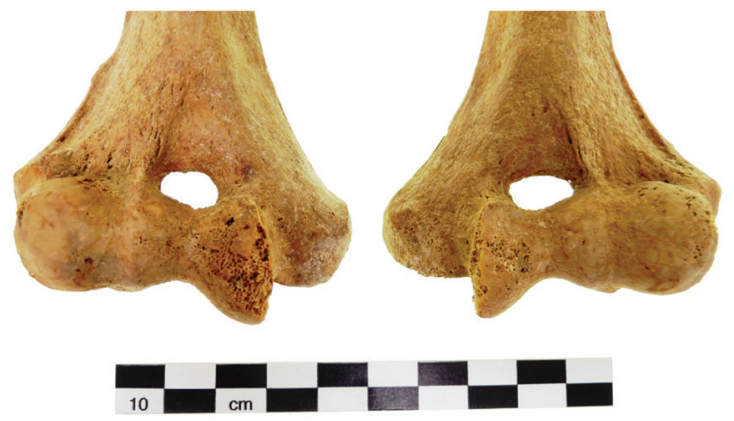

Figure 1. Distal left and right humerus with septal aperture (anterior view).

of researchers have suggested that septal aperture is simply connected with the impingement on the humeral septum by the olecranon and the coronoid process (a wider range of flexion and extension at the elbow joint, an overgrown coronoid or the olecranon process - mechanical theory) $[3,12,22,37]$. There are some other assumptions regarding the aetiology of the subtrochlear foramen, namely to connect the septal aperture with bone robusticity $[2,3,38,43]$, osteoarthritis, or osteoporosis [32]. However, the results have been questioned [22].

Because of the ambiguity of septal aperture causes, it seems to be necessary to continue the analysis of the problem. To check the validity of mechanical theory, the correlation between the subtrochlear foramen and musculoskeletal stress markers has been analysed in this study. It could be expected that individuals with septal aperture would have more developed muscles. Musculoskeletal stress markers (MSM) [16], (called also as entheseal changes, entheses) [1, 45], are bone changes manifested as increased complexity of the surface where a muscle, a tendon or a ligament inserts onto the periosteum and into the bony cortex $[4,30]$, in response to the force connecting with physical activity $[13,40]$. That is why MSMs had been widely used as general level markers of physical activity in past populations $[10,13,25,36,40]$.

Some authors $[2,3,38,43]$ have found that less robust humeri are more likely to have septal perforation. Bone robusticity refers to the strength of the bone in terms of its shape and size [42]. It has been known that bones adapt their structure to mechanical loading, and increased mechanical forces lead to greater bone robusticity [21]. By taking the mechanical theory of septal aperture formation, it can be assumed that more robust (more physically loaded) individuals should have a greater tendency to septal aperture.
So far, researchers have not been able to give any plausible explanation for the aetiology of septal aperture. Taking this uncertainty into consideration, according to its cause, further studies seem to be necessary. Knowledge about the phenomenon of subtrochanter aperture is important for anthropological and medical science. The aim of the present study is to examine the prevalence of septal aperture according to sex, skeletal side, age, and to investigate the correlation between septal aperture and MSM, and humeral robusticity. This analysis could be a link for researches on subtrochlear foramen aetiology.

\section{MATERIALS AND METHODS}

The sample comes from a medieval $\left(10^{\text {th }}\right.$ to $14^{\text {th }}$ century) burial site in Cedynia, Poland. Skeletons of 102 males (66 young adult, 54 middle adult), and 99 females (61 young adult, 38 middle adult) had been examined. Recommended methods had been applied to estimate the age and sex of the individuals $[7,11]$. Age had been estimated through the analysis of the degree of changes on the surface of pubic symphysis and cranial suture obliteration. The age classes were based on Buikstra and Ubelaker [7]: young adults (20-34 years), middle aged adults (35-49 years). According to the high frequency of bone degenerative changes, individuals older than 50 years had not been included. Features of the cranium and pelvis had been assessed for sex estimation.

Septal aperture had been scored as absent (0) or present (1). The frequencies of septal aperture were calculated according to age, sex, and skeletal side. A MSM analysis had been carried out based on the variability scale, developed by Myszka and Piontek [27]. Six muscle attachment sites had been analysed (Table 1). The attachment sites were assessed according to a three-point rating scale. Only changes of the robusticity type had been included in the scale [27].

Table 1. Musculoskeletal stress markers analysed on the skeletal material from Cedynia [27]

\begin{tabular}{lcc}
\hline Bone & Landmark & Site \\
\hline Scapula & Lateral margin & Teres minor origin \\
& Glenoid tubercle & Triceps origin \\
\hline Humerus & Bicipital groove & Pectoralis major insertion \\
& Deltoid tuberosity & Deltoid insertion \\
\hline Radius & Bicipital tuberosity & Biceps insertion \\
& Midshaft & Pronator teres origin \\
\hline
\end{tabular}


Table 2. Statistical characteristics of humeral measurements, humeral robusticity index (HRI) and mean value of upper limbs musculoskeletal stress markers (MSM)

\begin{tabular}{|c|c|c|c|c|c|c|c|c|c|c|c|c|}
\hline \multirow[t]{3}{*}{ Feature } & \multicolumn{6}{|c|}{ Males } & \multicolumn{6}{|c|}{ Females } \\
\hline & \multicolumn{3}{|c|}{ Left } & \multicolumn{3}{|c|}{ Right } & \multicolumn{3}{|c|}{ Left } & \multicolumn{3}{|c|}{ Right } \\
\hline & $\mathbf{N}$ & $x$ & SD & $\mathbf{N}$ & $x$ & SD & $\mathbf{N}$ & $x$ & SD & $\mathbf{N}$ & $x$ & SD \\
\hline M-1 & 59 & 330 & 12,8 & 86 & 336 & 12,4 & 50 & 300 & 15,7 & 68 & 305 & 15,5 \\
\hline M-7 & 80 & 63 & 4,0 & 84 & 64 & 4,9 & 62 & 57 & 4,99 & 65 & 57 & 5,5 \\
\hline HRI & 59 & 18.9 & 1.15 & 80 & 19.0 & 1.47 & 50 & 19 & 1.53 & 61 & 18.5 & 2.9 \\
\hline xMSM & 89 & 1.92 & 0.37 & 89 & 1.94 & 0.42 & 81 & 1.72 & 0.48 & 83 & 1.78 & 0.44 \\
\hline
\end{tabular}

M-1 — maximum length; M-7 - minimum shaft circumference; $x$ - mean; SD — standard deviation; xMSM — mean MSM

Table 3. Frequencies of septal aperture with respect to sex and skeletal side, and Mann-Whitney sex differences in septal aperture prevalence

\begin{tabular}{|c|c|c|c|c|c|c|c|c|}
\hline & \multicolumn{3}{|c|}{ Males } & \multicolumn{3}{|c|}{ Females } & \multicolumn{2}{|c|}{ Males vs. females } \\
\hline & $\mathbf{N}$ & n & $\%$ & $\mathbf{N}$ & n & $\%$ & $\mathbf{U}$ & $\mathbf{p}$ \\
\hline Left & 66 & 5 & 7.6 & 53 & 4 & 7.6 & 1748 & 0.91 \\
\hline Right & 64 & 6 & 9.4 & 56 & 3 & 5.4 & 1720 & 0.71 \\
\hline All & 130 & 11 & 8.5 & 109 & 7 & 6.4 & & \\
\hline
\end{tabular}

${ }^{*}$ Statistically significant at $\mathrm{p} \leq 0.05 ; \mathrm{N}$ - number of humeri; $\mathrm{n}$ - number of humeri with septal aperture; \% - frequency of humeri with septal aperture

Changes of stress lesions and ossification are morphological variations of pathological changes in tendon attachments, called enthesopathies [4, 19, 44]. For each individual, an aggregate MSMs score had been calculated as the main value from all available muscle attachment sites [46].

Humeral robusticity had been calculated using the humeral robusticity index: $\mathrm{HRI}=(\mathrm{M} 7 / \mathrm{M} 1) \times 100$; where $\mathrm{M} 1$ is the maximum length and $M 7$ is the minimum shaft circumference. The measurements were taken by using the techniques proposed by Martin and Saller [20].

The Spearman rank order correlation coefficients had been used to evaluate the relationship between septal aperture and other features (MSMs, HRI). Septal aperture had been tested for significant age, and sex differences, using Mann-Whitney tests. Differences between the frequencies of septal aperture on the right and left humerus had been calculated by use of the $\chi^{2}$ test for $2 \times 2$ tables. Critical alpha-levels had been set at 0.05 . Statistical analyses had been preceded by use of Statistica 10.0 PL software.

\section{RESULTS}

A statistical characteristic for humeral measurements, the HRI, and the main value from all available muscle attachment sites of the upper limb (xMSM) has been provided in Table 2 .

The frequency of septal aperture among the population from Cedynia is $7.5 \%$. In this skeletal group males have a slightly higher frequency of septal aperture in comparison to females (right skeletal side), and the frequency of this trait is similar on the left skeletal side. But the differences are not statistically significant. The frequency data for septal aperture according to sex, skeletal side and Mann-Whitney sex differences have been provided in Table 3.

In males, septal aperture has been more frequently observed on the right humerus, while among females, on the left humerus. However, neither sex differences between the frequency of septal aperture on the left and right skeletal side prove significant (males: $\chi^{2}=0.14 ; \mathrm{p}=0.71 ; \mathrm{df}=1$; females: $\chi^{2}=$ $=0.22 ; p=0.64 ; \mathrm{df}=1$ ). The raw frequency of septal aperture according to the skeletal side has been provided in Table 4.

In the material from Cedynia, the differences between the prevalence of septal aperture among young adults and middle aged adults had not been observed; however, septal aperture has been more frequently observed among younger individuals, both in men and in female. The frequency data for septal 
Table 4. Septal aperture frequencies in Cedynia sample

\begin{tabular}{|c|c|c|c|c|c|c|c|c|}
\hline \multirow[t]{2}{*}{ Sex } & \multicolumn{8}{|c|}{ L/R } \\
\hline & $1 / 1$ & $1 / 0$ & $0 / 1$ & $1 /-$ & $-/ 1$ & $0 /-$ & $-/ 0$ & $0 / 0$ \\
\hline Males & 5 & 0 & 1 & 0 & 0 & 6 & 5 & 53 \\
\hline Females & 1 & 2 & 2 & 1 & 0 & 0 & 4 & 47 \\
\hline
\end{tabular}

Table 5. Frequencies of septal aperture with respect to age, and Mann-Whitney sex differences in septal aperture prevalence

\begin{tabular}{|c|c|c|c|c|c|c|c|c|c|c|c|}
\hline \multirow[t]{2}{*}{ Side } & \multirow[t]{2}{*}{ Age } & \multicolumn{5}{|c|}{ Males } & \multicolumn{5}{|c|}{ Females } \\
\hline & & $\mathbf{N}$ & $\mathbf{n}$ & $\%$ & $\mathbf{U}$ & $\mathbf{p}$ & $\mathbf{N}$ & $\mathrm{n}$ & $\%$ & $\mathbf{U}$ & $\mathbf{p}$ \\
\hline \multirow[t]{2}{*}{ L } & YA & 40 & 3 & 7.5 & \multirow{2}{*}{519.0} & \multirow{2}{*}{0.99} & 33 & 3 & 9.1 & \multirow{2}{*}{341.0} & \multirow{2}{*}{0.16} \\
\hline & MA & 26 & 2 & 7.7 & & & 20 & 1 & 5.0 & & \\
\hline \multirow[t]{2}{*}{$\mathrm{R}$} & YA & 38 & 4 & 10.5 & \multirow{2}{*}{480.0} & \multirow{2}{*}{0.85} & 35 & 3 & 8.8 & \multirow{2}{*}{316.0} & \multirow{2}{*}{0.18} \\
\hline & MA & 26 & 2 & 7.7 & & & 23 & 0 & 0.0 & & \\
\hline
\end{tabular}

*Statistically significant at $p \leq 0.05 ; N$ - number of humeri; $n$ - number of humeri with septal aperture; \% — frequency of humeri with septal aperture; $L$ - left humeri; $R$ - right humeri; YA — young adult; MA — middle adult

aperture according to age, and Mann-Whitney age differences, have been provided in Table 5.

In the analysed material, males with less developed muscle markers (xMSM) of the right upper bone had proved more predicted to have septal aperture $(R=-0.34)$. For the left bones and among females, the converse correlation had also been shown; however, the result did not prove to be statistically significant (Table 6).

\section{DISCUSSION}

In the population from Cedynia, the frequency of septal aperture had been $7.5 \%$. There were no statistically significant differences between septal aperture according to sex, skeletal side, and age. Therefore, this feature had been more frequently observed among males (8.5\%). Lamina perforation among males had frequently been observed on the right humerus, while among females and younger adults it was more frequent on the left humerus, resulting in more septal apertures than in older ones (all these differences insignificant). These results are in contradiction to the majority of studies, where it was more prevalent in females [2, 17, 29, 32, 33, 43], and left asymmetry has commonly been observed $[2,17,18,23,29,33,34,35,43]$. However, there are reports of higher incidence of subtrochanter foramen among males [12, 24]. Diwan et al. [9] have shown similar frequencies of septal aperture in both sexes. There are studies where the dominance of the right humerus in septal aperture frequency has been ob-
Table 6. Spearman rank order correlation coefficient (R) among septal aperture and mean value from all available muscle attachment sites of upper limb (xMSM), and humeral robusticity index (HRI)

\begin{tabular}{lcclll}
\hline & \multicolumn{2}{c}{ Males } & & \multicolumn{2}{c}{ Females } \\
\cline { 2 - 3 } \cline { 5 - 6 } & Left & Right & & Left & Right \\
\hline XMSM & -0.21 & $-0.34^{*}$ & & -0.24 & -0.07 \\
HRI & -0.19 & -0.11 & & -0.16 & -0.14 \\
\hline
\end{tabular}

*Statistically significant at $p \leq 0.05$

served [28, 39]; and there are also studies where the similar incidence of septal aperture on both sides has been observed [39].

In the analysed skeletal material, males with stronger muscles (MSMs) have tended to have less septal aperture (a significant correlation observed on right humerus). Mays [22] has pointed out that the architecture and motion of the soft tissue (tightness/ /laxity of ligamentous and/or muscles) can play a role in septal aperture formation. It can be hypothesized that hypermobility of the elbow, as a consequence of ligamentous and/or muscles laxity, could be the reason of increased impingement of ulnar processes on the septum [22]. Weaker muscles can lead to higher joint laxity that causes joint hypermobility, impingement of coronoid and olecranon processes on the humeral lamina, which can finally lead to septal aperture formation [22, 32]. It may be stated that 
stronger muscles prevent septal aperture by decreasing joint looseness. However, this thesis cannot be taken without any caution, and some limitations must be considered. Firstly, a small sample size must be taken into consideration when interpreting the results. Secondly, although muscle markers have been treated in anthropology as markers of physical activity $[10,13,16,25,36,40]$, most anthropologists agree that MSMs aetiology is multifactorial, and emphasize the role of factors other than physical activity, such as age, body size, hormones, or genes in MSMs development [for the detailed discussion see 14, 30, 45, 47].

Some authors $[2,3,38,43]$ have found that a less robust humerus is more likely to have septal perforation. Mays [22] is sceptical, indicating that Trotter [43] gives little evidence that bones without septal aperture are heavier. Benfer and McKern [2] analyse only one comparison of the converse relationship between septal perforation and humeral dimensions. In our study, the correlation between septal aperture and humeral robusticity is converse, yet small and insignificant. On the basis of the results collected by Benfer and Tappen [3], Mays [22] have suggested that in a larger humerus the contact of ulna processes, with septal lamina, can be insufficient to cause septal aperture, and therefore, more robust bones prevent lamina perforation. However, this thesis demands further study. Moreover, a more detailed analysis of the ulna process size and trochlear notch are needed.

Taking into account that number of conducted studies, we may confirm that individuals with more massive bones have stronger muscles $[5,26,31,41,47]$, and also suggest the same aetiology of muscle markers and bone robusticity should not be surprising. However, this requires caution, as some researchers are sceptical towards the existence of the relationship between bone robusticity and muscle marker formation, underlining the multifactorial aetiology of bone development $[6,41,48]$.

\section{CONCLUSIONS}

It could be hypothesised, that the hypermobility of the elbow can be one of the causes of septal aperture occurrence. It can be speculated that stronger bones (heavier muscles, more robust bones) increase joint tightness, and therefore, protect the humeral lamina from perforation. Verification of this thesis seems to be important for anthropological and medical science. For anthropologists, it could be important for the reliable reconstruction of past population's lifestyles.
For medical sciences, however, it could prove helpful in humeral fracture preventing. Therefore, further examination of aetiological factors of septal aperture are needed.

\section{ACKNOWLEDGEMENTS}

I would like to thank Sylwia Łukasik for taking the photographs of septal aperture.

\section{REFERENCES}

1. Alves Cardoso FA, Henderson CY (2010) Enthesopathy formation in the humerus: data from known age at-death and known occupation skeletal collection. Am J Phys Anthropol, 141: 550-560.

2. Benfer RA, McKern TW (1966) The correlation of bone robusticity with the perforation of the coronoid-olecranon septum in the humerus of man Am J Phys Anthropol, 24: 247-256.

3. Benfer RA, Tappen NC (1968) The occurrence of septal perforation of the humerus in the non-human primate species Am J Phys Anthropol, 29: 19-28.

4. Benjamin M, Kumai T. Milz S. Boszczyk BM, Boszczyk AA, Ralphs JR (2002) The skeletal attachment of tendon-tendon 'entheses'. Comp Biochem Physiol, 133: 931-945.

5. Berget KA, Churchill SE (1994) Subsistence activity and humeral hypertrophy among Western Aleutian islanders Am J Phys Anthropol, 18: 55 [abstract].

6. Bridges PS (1997) The relationship between muscle markings and diaphyseal strength in prehistoric remains from west-central Illinois Am J Phys Anthropol, 24, 82 [abstract].

7. Buikstra JE, Ubelaker DH (1994) Standards for data collection from human skeletal remains. Arkansas Archeological Survey Research, 44.

8. De Wilde $\mathrm{V}$, De Maeseneer M, Lenchik L, Van Roy P, Beeckman P, Osteaux M (2004) Normal osseous variants presenting as cystic or lucent areas on radiography and CT imaging: a pictorial overview. Eur J Radiol, 51: 77-84.

9. Diwan RK, Rani A, Rani A, Chopra J, Srivastava AK, Sharma PK, Verma RK, Pankaj AK (2013) Incidence of supratrochlear foramen of humerus in North Indian population. Biomed Res-India, 24/1: 142-145.

10. Eshed V, Gopher A, Galili E, Hershkovitz I (2004) Musculoskeletal stress markers in Natufian hunter-gatherers and Neolithic farmers in the Levant: the upper limb. Am J Phys Anthropol, 123: 303-315.

11. Ferembach D, Schwidetzky I, Stloukal M (1979) Empfehlungen für die alters- und Geschlechtsdiagnose am Skelett Homo, 30: 1-32.

12. Granville EV (1967) Perforation of the coronoid-olecranon septum humero-ulnar relationship in Netherlands and African populations Am J Phys Anthropol, 26: 85-92.

13. Hawkey DE, Merbs CF (1995) Activity-induced musculoskeletal stress markers (MSM) and subsistence strategy changes among ancient Hudson Bay Eskimo Int J Osteoarchaeol, 5: 324-338.

14. Henderson CY, Alves Cardoso FA (2013) Special issue entheseal changes and occupation: technical and theoretical advances and their application Int J Osteoarchaeol, 23: 127-134. 
15. Kate BR, Budey PN (1970) A note on a septal apertures in the humerus in the humerus of Central Indians. Eastern Anthropologist, 33: 105-110.

16. Kennedy KAR (1998) Markers of occupational stress: conspectus and prognosis of research. Int J Osteoarchaeol, 8: 305-310.

17. Koyun N, Aydinlioğlu A, Gümrukcüoğlu FN (2011) Aperture in coronoi-olecranon septum: A radiological evaluation. Indian J Orthop, 45/5: 392-395.

18. Krishnamurthy $A$, Yelicharla AR, Takkalapalli A, Manishamappa V, Bovinndala B, Chandramohan M (2011) Supratrochlear foramen of humerus: a morphometric study. Int J Biol Med Res, 2/3: 829-831.

19. Mariotti V, Facchini F, Belcastro MG (2004) Enthesopathies - proposal of a standardized scoring method and applications. Coll Anthropol, 28: 145-159.

20. Martin R, Saller K (1957) Lehrbuch der Antropologie in Systematischer Darstellung mit Besonderer Berücksichtigung der Antropoloschen Methoden. Gustav Fischer Verlag, Stuttgard.

21. Mays S (2001) Effects of age and occupation on cortical bone in a group of 18th-19th century British men. Am J Phys Anthropol, 116: 34-44.

22. Mays S (2008) Septal aperture of the humerus in a mediaeval human skeletal population. Am J Phys Anthropol, 136: 432-440.

23. Mayuri J, Aparna T, Pradeep P, Smita M (2013) Anatomical study of supratrochlear foramen of humerus. J Res Med Den Sci, 1/2: 33-35.

24. Meier LN, Hunt DR (2006) Incidence of humeral septal aperture and its relation to population and sex. Am J Phys Anthropol, 42 (suppl.): 129.

25. Molnar P (2006) Tracing prehistoric activities: Musculoskeletal stress markers of a Stone-Age population on the island of Gotland in the Baltic Sea. Am J Phys Anthropol, 129: 12-23.

26. Myszka A, Piontek J (2011) Shape and size of the body vs. musculoskeletal stress markers. Anthropol Anzeiger, 68/2: 139-152

27. Myszka A, Piontek J (2012) Variation of musculoskeletal stress markers in the medieval population from Cedynia (Poland): proposal of standardized scoring method application. Coll Anthropol, 36/3: 1009-1017.

28. Nayak SR, Das S., Krishnamurthy A, Prabhu LV, Potu BK (2009) Supratrochlear foramen of the humerus: an anatomico-radiological study with clinical implication. Upsala J Med Sci, 114: 90-94.

29. Ndou R, Smith P, Gemell R, Mohatla O (2013) The supratrochlear foramen of the humerus in a South African Dry Bone Sample. Clin Anat, 26: 870-874.

30. Niinimäki S (2011) What do muscle marker ruggedness scores actually tell us? Int J Osteoarchaeol, 21: 292-299.

31. Niinimäki S (2012) The relationship between musculoskeletal stress markers and biomechanical properties of the humeral diaphysis. Am J Phys Anthropol, 147: 618-628.
32. Papaloucas C, Papaloucas M, Stergiulas A (2011) Rare cases of humerus apertures in Greeks. Trends Med Res, 6/3: 178-183.

33. Paraskevas GK, Papaziogas B, Tzaveas A, Gliaglis G, Kitsoulis $P$, Natsis $K$ (2010) The supratrochlear foramen of the humerus and its relation to the medullary canal: a potential surgical application. Med Sci Monit, 16/4: 119-123.

34. Patel SV, Sutaria LK, Nayak TV, Kanjiya DP, Patel BM, Aterkar SH (2013) Morphometric study of supratrochlear foramen of humerus. Int J Biomed Advance Research, 4/2: 89-92.

35. Raghavendra K, Reddy AK, Shirol VS, Dixit D, Desai SP (2014) Morphometric analysis of septal aperture in humerus. Int J Med Res Health Sci, 3/2: 269-272.

36. Robb JE (1998) The interpretation of skeletal muscle sites: a statistical approach. Int J Osteoarchaeol, 8: 363-377

37. Scheuer L, Black S (2000) The Upper Limb. In: Scheuer L, Black SM eds. Developmental Juvenile Osteology. Academic Press, London, UK, 277-278.

38. Silveira FBC, Junior VM, Fazan VPS (2007) Anthropometric evaluation of the humerus in the presence and absence of the septal foramen. Int J Morphol, 25: 158 (abstract).

39. Singhal S, Rao V (2007) Supratrochlear foramen of the humerus. Anat Sci Int, 82: 105-107.

40. Steen SL, Lane RW (1998) Evaluation of habitual activities among two Alaskan Eskimo populations based on musculoskeletal stress markers. Int J Osteoarchaeol, 8: 341-353.

41. Stirland AJ (1998) Musculoskeletal evidence of activity: problems of evaluation. Int J Osteoarchaeol, 8: 354-362.

42. Stock JT, Shaw CN (2007) Which measures of diaphyseal robusticity are robust? A comparison of external methods of quantifying the strength of long bone diaphysis to cross-sectional geometric properties. Am J Phys Anthropol, 134: 412-423.

43. Trotter M (1934) Septal apertures in humerus of American whites and Negroes American. Am J Phys Anthropol, 19: 213-227.

44. Villotte S, Castex D, Couallier V, Dutour O, Knüsel CJ, Henry-Gambier D (2010) Enthesopathies as occupational stress markers: evidence from the upper limbs. Am J Phys Anthropol, 142: 224-234.

45. Villotte S, Knüsel CJ (2013) Understanding entheseal changes: De nition and life course changes. Int J Osteoarchaeol, 23: 135-146.

46. Weiss E (2003) Understanding muscle markers: aggregation and construct validity. Am J Phys Anthropol, 121, 230-240.

47. Weiss E (2007) Muscle markers revisited: activity pattern reconstruction with controls in a Central California Amerind population. Am J Phys Anthropol, 133: 931-940.

48. Weiss E, Corona L, Schultz B (2012) Sex differences in musculoskeletal stress markers: problems with activity pattern reconstruction. Int J Osteoarchaeol, 22: 70-80. 